\title{
Self-reported sitting time is not associated with incidence of cardiovascular disease in a population-based cohort of mid-aged women
}

\author{
Gerrie-Cor M Herber-Gast ${ }^{1 \dagger}$, Caroline A Jackson ${ }^{1 * \dagger}$, Gita D Mishra ${ }^{1}$ and Wendy J Brown ${ }^{2}$
}

\begin{abstract}
Background: In Westernised societies adults are increasingly spending many hours each day in sedentary, low energy expenditure activities such as sitting. Although there is growing evidence on the relationship between television/screen time and increased cardiovascular disease mortality, very little is known about the association between total sitting time (in different domains) and cardiovascular disease incidence. We investigated this in a population-based cohort of mid-aged women in Australia.
\end{abstract}

Findings: Data were from 6154 participants in the 1946-51 birth cohort of the Australian Longitudinal Study on Women's Health who were free of cardiovascular disease at baseline. Survival analysis was used to determine the association between self-reported sitting time and cardiovascular disease incidence, determined through hospital diagnoses and cause of death data. During a mean ( \pm SD) follow-up time of $9.9 \pm 1.2$ years, 177 cases of cardiovascular disease occurred. Mean sitting time ( \pm SD) was $5.4 \pm 2.6$ hours a day. Sitting time was not associated with incident cardiovascular disease (adjusted hazard ratio $0.97,95 \% \mathrm{Cl} 0.92$ to 1.03 ). We found no interaction between physical activity and sitting time and cardiovascular disease.

Conclusions: In mid-aged women sitting time does not appear to be associated with cardiovascular disease incidence. These findings are contrary to expectations, given the growing evidence of a relationship between sitting time and cardiovascular disease mortality. Research in this area is scarce and additional studies are needed to confirm or refute these findings.

Keywords: Sitting time, Sedentary behaviour, Cardiovascular disease, Women

\section{Findings} Introduction

In Westernised societies many adults spend much of their day engaged in sedentary activities that involve low energy expenditure [1]. Recent reviews have found that sedentary behaviour is associated with increased risk of adverse health outcomes in adults, and that this is independent of physical activity level [2,3]. Several studies have demonstrated a relationship between sedentary behaviour and cause-specific mortality, including cardiovascular disease (CVD) mortality. A meta-analysis of

\footnotetext{
* Correspondence: caroline.jackson@uq.edu.au

${ }^{\dagger}$ Equal contributors

${ }^{1}$ Centre for Longitudinal and Life course Research, School of Population Health, University of Queensland, Public Health Building, Herston Road, Herston, QLD 4006, Australia

Full list of author information is available at the end of the article
}

eight studies found a 90\% increased risk of CVD mortality when high versus low sedentary groups were compared [3]. However, the relationship with disease-specific incidence, including CVD incidence, is less clear and has been under-researched [2,3]. Of just four studies that have assessed sedentary behaviour and risk of incident CVD, [4-7] three found that higher television or screenbased viewing time was associated with significantly increased risk of CVD incidence. Only one of these studies defined sedentary behaviour as total sitting time [5]; it found an increased risk of CVD among women who spent at least 16 hours per day sitting, compared with those who sat for less than four hours per day [5]. Our aim was therefore to investigate the association between sitting time and CVD incidence in a prospective study of mid-aged women in Australia. 


\section{Methods}

We used data from participants in the Australian Longitudinal Study on Women's Health (ALSWH), a national population-based study of women born in 1921-26, 1946-51 and 1973-78. Women were randomly selected from the Medicare database, which covers all citizens and permanent residents of Australia, including refugees and immigrants, with intentional oversampling of women living in rural and remote areas. Further details of the study are described elsewhere [8]. ALSWH was approved by the Human Research Ethics Committee of University of Newcastle, the Medical Research Ethics Committee of the University of Queensland and the Departmental Ethics Committee of the Australian
Government Department of Health and Ageing. The study complies with the Helsinki Declaration.

Our focus was on the 1946-51 cohort, who were surveyed in 1996, 1998 and every three years thereafter. In these analyses, we included those who responded to survey three in $2001(n=10,628)$, and who lived in the states of New South Wales (NSW), Queensland (QLD) or Western Australia (WA), giving a total of 6739 women. Linked hospital admission data were not available for the other states, and were not available for NSW or QLD prior to 2000. We excluded women with prevalent heart disease or stroke, based on 2001 selfreport and hospital admission data $(\mathrm{n}=327)$, and with missing data on sitting time $(n=173)$ or any of the

Table 1 Demographic and health characteristics of the participants, by sitting time and CVD

\begin{tabular}{|c|c|c|c|c|c|c|}
\hline & \multirow[b]{2}{*}{$\begin{array}{l}\text { Total group } \\
(n=6,154)\end{array}$} & \multicolumn{3}{|c|}{ Sitting time } & \multirow[b]{2}{*}{$\begin{array}{c}\text { No CVD } \\
(n=5,977)\end{array}$} & \multirow[b]{2}{*}{$\begin{array}{c}\text { CVD } \\
(n=177) \\
\end{array}$} \\
\hline & & $\begin{array}{c}\text { Low } \\
(n=1,860)\end{array}$ & $\begin{array}{l}\text { Moderate } \\
(n=2,232)\end{array}$ & $\begin{array}{c}\text { High } \\
(n=2,062)\end{array}$ & & \\
\hline Age & $52.5 \pm 1.5$ & $52.5 \pm 1.5$ & $52.5 \pm 1.5$ & $52.5 \pm 1.4$ & $52.5 \pm 1.5$ & $52.8 \pm 1.4$ \\
\hline Sitting time, hours/day & $5.4 \pm 2.6$ & $2.7 \pm 0.8$ & $4.9 \pm 0.7$ & $8.4 \pm 1.8$ & $5.4 \pm 2.6$ & $5.2 \pm 2.3$ \\
\hline Follow-up time, months & $118.6 \pm 14.5$ & $118.8 \pm 13.5$ & $118.2 \pm 16.0$ & $119.1 \pm 13.7$ & $120.2 \pm 10.0$ & $67.0 \pm 34.5$ \\
\hline CVD case, yes & $177(2.9)$ & $48(3.1)$ & $57(3.0)$ & $47(2.7)$ & & \\
\hline \multicolumn{7}{|l|}{ Educational level } \\
\hline No formal qualifications & $914(14.9)$ & $307(16.5)$ & $351(15.7)$ & $256(12.4)$ & $888(14.9)$ & $26(14.7)$ \\
\hline School or leaving certificate & $3,130(50.9)$ & $964(51.8)$ & $1,113(49.9)$ & $1,053(51.1)$ & $3,045(51.0)$ & $85(48.0)$ \\
\hline Trade/apprenticeship or higher education & $2,110(34.3)$ & $589(31.7)$ & $768(34.4)$ & $753(36.5)$ & 2,044 (34.2) & $66(37.3)$ \\
\hline \multicolumn{7}{|l|}{ BMI $\left(k g / m^{2}\right)$} \\
\hline Underweight $(<18.5)$ & $96(1.6)$ & $36(1.9)$ & $24(1.1)$ & $36(1.8)$ & 93 (1.6) & $3(1.7)$ \\
\hline Healthy weight (18.5-24.9) & $2,678(43.5)$ & $912(49.0)$ & $967(43.3)$ & $799(38.8)$ & $2,606(43.6)$ & $72(40.7)$ \\
\hline Overweight (25-30) & $2,014(32.7)$ & $588(31.6)$ & $760(34.1)$ & $666(32.3)$ & $1,953(32.7)$ & $61(34.5)$ \\
\hline Obese $(>30)$ & $1,366(22.2)$ & $324(17.4)$ & $481(21.6)$ & $561(27.2)$ & $1,325(22.2)$ & $41(23.2)$ \\
\hline \multicolumn{7}{|l|}{ Physical activity* } \\
\hline Nil/sedentary & $1,097(17.8)$ & $300(16.1)$ & $362(16.2)$ & $435(21.1)$ & $1,057(17.7)$ & $40(22.6)$ \\
\hline Low & 2,297 (37.3) & $690(37.1)$ & $793(35.5)$ & $814(39.5)$ & $2,231(37.3)$ & $66(37.3)$ \\
\hline Moderate & $1,232(20.0)$ & $369(19.8)$ & $462(20.7)$ & $401(19.5)$ & $1,206(20.2)$ & $26(14.7)$ \\
\hline High & $1,528(24.8)$ & $501(26.9)$ & $615(27.6)$ & $412(20.0)$ & $1,483(24.8)$ & $45(25.4)$ \\
\hline \multicolumn{7}{|l|}{ Smoking status } \\
\hline Non-smoker & $3,727(60.6)$ & $1,153(62.0)$ & $1,361(61.0)$ & $1,213(58.8)$ & $3,627(60.7)$ & $100(56.5)$ \\
\hline Ex-smoker & $1,546(25.1)$ & $458(24.6)$ & $549(24.6)$ & $539(26.1)$ & $1,500(25.1)$ & $46(26.0)$ \\
\hline Current smoker & $881(14.3)$ & $249(13.4)$ & $322(14.4)$ & $310(15.0)$ & $850(14.2)$ & $31(17.5)$ \\
\hline \multicolumn{7}{|l|}{ Alcohol consumption $†$} \\
\hline Low risk drinker & $3,285(53.4)$ & $943(50.7)$ & $1,184(53.1)$ & $1,158(56.2)$ & $3,190(53.4)$ & $95(53.7)$ \\
\hline Non-drinker & $782(12.7)$ & $256(13.8)$ & $295(13.2)$ & $231(11.2)$ & $762(12.8)$ & $20(11.3)$ \\
\hline Rarely drinker & $1,717(27.9)$ & $549(29.5)$ & $631(28.3)$ & $537(26.0)$ & $1,660(27.8)$ & $57(32.2)$ \\
\hline Risky drinker & $370(6.0)$ & $112(6.0)$ & $122(5.5)$ & $136(6.6)$ & $365(6.1)$ & $5(2.8)$ \\
\hline
\end{tabular}

*Defined in MET. Min/week as: Nil/sedentary - <40 MET; low - 40-299; moderate - 300-599; high - $\geq 600$.

†'Risky drinkers' (15 to 28 drinks per week) and 'High risk drinkers' (More than 28 drinks per week) were grouped together. For women identified as low risk $(<15$ drinks per week) by the NHMRC guidelines, we separately categorised those classified as low-risk drinkers from those reporting that they drink only rarely. 
covariates $(n=85)$, thereby including data from 6154 women in the analyses.

Sitting time was assessed by asking: 'How many hours each day do you typically spend sitting down while doing things like visiting friends, driving, reading, watching television or working at a desk or computer (a) on a usual week-day and (b) on a usual weekend-day?' Sitting time data were cleaned using protocols developed by van Uffelen et al. and mean sitting time in hours/day was calculated as ((weekday sitting $\times 5+$ weekend day sitting $\times 2) / 7$ ) [9].

Covariates included demographic (age, education level and marital status) and lifestyle factors (body mass index (BMI), smoking status, physical activity [10] and alcohol consumption, defined in light of the Australian National Health and Medical Research Council guidelines [11]), categorised as shown in Table 1.

Data on morbidity were obtained from hospital admitted patient discharge data from 2001 to 2010 for NSW, 2001-2011 for WA and QLD public hospitals, and from July 2007 through 2011 for QLD private hospitals. Nonfatal and fatal CVD events were identified using International Statistical Classification of Diseases and Related Health Problems codes (9th revision (ICD-9): 410-414, 430-438; or 10th revision (ICD-10): I20-I25, I60-I67, and I69). If multiple CVD events occurred, the first diagnosis was taken as the endpoint. Women were followed from the month of return of survey three (2001) until the first nonfatal CVD event, death, or were censored at 31 December 2010 (NSW), 16 June 2011 (WA) or 16 December 2011 (QLD). Information on vital status was available through linkage to the National Death Index.

Statistical analyses were performed using SAS 9.2 software. Baseline characteristics were described according to sitting time tertiles by means and SDs for normally distributed continuous variables and numbers and percentages for categorical variables. Cox proportional hazards models were used to estimate hazard ratios (HRs) and 95\% confidence intervals (CIs) of CVD risk for continuous data and tertiles of sitting time using the lowest tertile as the reference.

For univariable analyses, a model was fitted for sitting time and risk of CVD (model 1). Multivariable models included age, education, smoking and alcohol consumption (model 2), physical activity (model 3) and BMI (model 4). We also formally tested effect modification by adding interaction terms between sitting time and physical activity. Differences with P-values $<0.05$ were considered to be statistically significant.

\section{Results}

Mean age at baseline (2001) was $52.5 \pm 1.5$ years. Mean sitting time was $5.4 \pm 2.6$ hours a day. Compared with women in the lowest category of sitting time, those with the highest sitting time were more educated and more likely to be obese, low risk alcohol drinkers, and less physically active (Table 1). During a mean follow-up of $9.9 \pm 1.2$ years, 177 CVD events occurred, of which four were fatal.

Sitting time (as a continuous variable) was not associated with risk of CVD; this pattern did not change after adjustment for potential confounders (HR 0.97, 95\% CI 0.92, 1.03); Table 2, model 4). In anticipation that only high levels of sitting time may be associated with CVD risk, we also analysed sitting time as a categorical variable, but found no associations with CVD (Table 2).

Formal tests for interaction with physical activity revealed no significant interactions ( $\mathrm{p}$-values for effect modification were 0.76 and 0.84 for the continuous and categorical sitting time variables respectively).

\section{Discussion}

We found no association between sitting time and incidence of CVD among mid-aged women.

These findings are contrary to those expected, given that previous studies have shown a positive association between sedentary behaviour and CVD incidence [4-7], and between total sitting time and CVD mortality [12-14]. Differences in the exposure measure may partly explain this difference. All but one of the four studies of CVD incidence measured television viewing time $[4,7]$, or 'screen time' [6]. This type of sedentary behaviour may be associated with a different level of CVD risk compared with total sitting time, since it may be associated with long periods of uninterrupted sitting, or unhealthy eating patterns. Only one study (which principally compared relationships between walking and vigorous activity with CVD in women aged 50-79 at baseline) asked participants about total sitting time [5], as we did. This study found that sitting for 16 hours or more per day increased CVD risk by $68 \%$ compared with sitting for less than four hours

Table 2 Hazard ratios (95\% Cls) for sitting time and cardiovascular disease risk in the total study population $(\mathrm{N}=6,154)$

\begin{tabular}{|c|c|c|c|c|}
\hline & \multirow{2}{*}{$\begin{array}{l}\text { Sitting time } \\
\text { continuous }\end{array}$} & \multicolumn{3}{|c|}{ Sitting time in categories } \\
\hline & & Low & Moderate & High \\
\hline No. of cases & 177 & 48 & 57 & 47 \\
\hline Model 1 & $0.97(0.92,1.03)$ & Ref & $1.01(0.71,1.45)$ & $0.91(0.63,1.32)$ \\
\hline Model 2 & $0.98(0.92,1.03)$ & Ref & $1.03(0.72,1.48)$ & $0.93(0.64,1.35)$ \\
\hline Model 3 & $0.97(0.92,1.03)$ & Ref & $1.03(0.72,1.48)$ & $0.91(0.62,1.32)$ \\
\hline Model 4 & $0.97(0.92,1.03)$ & Ref & $1.03(0.72,1.47)$ & $0.90(0.62,1.32)$ \\
\hline $\begin{array}{l}\text { Interaction } \\
\text { with PA }\end{array}$ & 0.76 & & 0.84 & \\
\hline
\end{tabular}

Model 1: crude; Model 2: adjusted for age, education, smoking, alcohol consumption; Model 3: Model 2 and physical activity; Model 4: Model 3 and BMI. 
per day. Other durations of sitting were not associated with increased CVD risk.

Most previous studies similarly used hospital records and/or routinely collected mortality data to define CVD. However, the definition of CVD was generally much broader than in our study, which may partly explain the inconsistency in findings. The distribution of total sitting time in our study also differs, in that our participants appear to be less sedentary than in some other study populations [5,12]. The majority of women were in the middle range of sitting time, and even the highest tertile group had a mean sitting time of only 8.4 hours/day. Therefore, it is possible that overall sitting time was perhaps too low in our cohort to detect an impact on CVD incidence within the follow-up period. Differences in age of study population and physical activity levels do not appear to explain contrasting findings with previous studies on CVD incidence. Most participants were similarly middle-aged, and the physical activity levels, albeit measured in different ways, appear to be comparable. Among studies of sitting time and CVD mortality, participants included elderly people in two studies $[12,13]$, and although a third study included a comparable agegroup, the association between sitting time and mortality was not adjusted for confounders [14]. Interestingly, recent results from our group have shown that prolonged sitting time is associated with all-cause mortality in the cohort born 1921-1926 [15] and with breathing difficulties and chest pain [16] (which may be symptomatic of CVD) in the 1946-1951 cohort of ALSWH.

Our study has a number of strengths. The study population was large and community-based which improves the generalizability of our findings to mid-aged women. We ascertained CVD outcomes using an objective measure based on hospital admission and cause of death data. Studies using similar registries have shown that $89 \%$ of suspected CVD outcomes are confirmed against internationally agreed criteria [17], so that outcome misclassification is probably not a major issue in our study.

There are a few limitations. First, sitting time was based on self-report and bias may have been introduced if measurement error was related to occurrence of CVD. However, it is likely that any measurement error was random, which may have led to underestimation of any association between sitting time and CVD. Similar sitting time questions are used in the International Physical Activity Questionnaire, which, in women, have been shown to have good reliability and moderate criterion validity against accelerometers $(<100$ counts/min) [18]. Our study population was on average aged 52.5 years at baseline and despite following women for an average of 9.9 years, it may take longer for sitting time to impact on CVD in this particular age group. This may explain why sitting time was associated with possible CVD symptoms [16], but not CVD events. Second, the number of CVD events was relatively low. However, with this study size we were powered to detect a minimum relative risk of 1.17, which is much smaller than that observed in studies of sitting time and CVD mortality. Third, our study population included women only and we cannot assume that similar results would be observed in men. Finally, we did not have country-wide hospital admission data and thus would not have identified a small number of CVD outcomes that may have occurred outside included states.

In this study we did not find an association between sitting time and CVD incidence. Further large prospective population-based studies in different settings, age-groups and study populations, with objective measurement of both sitting time and CVD incidence, sufficiently long follow-up and a distinction between leisure time and occupational sitting time, are needed to confirm or refute our findings.

\section{Abbreviations}

CVD: Cardiovascular disease; HR: Hazard ratio; Cl: Confidence interval.

\section{Competing interests}

The authors declare that they have no competing interests.

\section{Authors' contributions}

GCMHG, CJ, WB and GM conceived and designed the study. GCMHG and $\mathrm{CJ}$ performed the analyses, interpreted the results and co-drafted the manuscript. WB and GM interpreted the results and commented on the draft manuscript. All authors read and approved the final manuscript.

\section{Acknowledgments}

The Australian Longitudinal Study on Women's Health was conceived and developed by groups of interdisciplinary researchers at the Universities of Newcastle and Queensland, is funded by the Australian Government

Department of Health and Ageing. GCMHG, CJ and GDM are supported by the Australian National Health and Medical Research Council Centre of Research Excellence grant (APP1000986).

\section{Author details}

${ }^{1}$ Centre for Longitudinal and Life course Research, School of Population Health, University of Queensland, Public Health Building, Herston Road, Herston, QLD 4006, Australia. ${ }^{2}$ School of Human Movement Studies, University of Queensland, Brisbane, Australia.

Received: 18 January 2013 Accepted: 1 May 2013

Published: 7 May 2013

\section{References}

1. Healy GN, Matthews CE, Dunstan DW, Winkler EA, Owen N: Sedentary time and cardio-metabolic biomarkers in US adults: NHANES 2003-06. Eur Heart J 2011, 32:590-597.

2. Thorp AA, Owen N, Neuhaus M, Dunstan DW: Sedentary behaviors and subsequent health outcomes in adults a systematic review of longitudinal studies, 1996-2011. Am J Prev Med 2011, 41:207-215.

3. Wilmot EG, Edwardson CL, Achana FA, Davies MJ, Gorely T, Gray LJ, Khunti K, Yates T, Biddle SJ: Sedentary time in adults and the association with diabetes, cardiovascular disease and death: systematic review and meta-analysis. Diabetologia 2012, 55:2895-2905.

4. Hawkes AL, Lynch BM, Owen N, Aitken JF: Lifestyle factors associated concurrently and prospectively with co-morbid cardiovascular disease in a population-based cohort of colorectal cancer survivors. Eur J Cancer 2011, 47:267-276 
5. Manson JE, Greenland P, LaCroix AZ, Stefanick ML, Mouton CP, Oberman A, Perri MG, Sheps DS, Pettinger MB, Siscovick DS: Walking compared with vigorous exercise for the prevention of cardiovascular events in women. N Engl J Med 2002, 347:716-725.

6. Stamatakis E, Hamer M, Dunstan DW: Screen-based entertainment time, all-cause mortality, and cardiovascular events: population-based study with ongoing mortality and hospital events follow-up. J Am Coll Cardiol 2011, 57:292-299.

7. Wijndaele K, Brage S, Besson H, Khaw KT, Sharp SJ, Luben R, Bhaniani A, Wareham NJ, Ekelund U: Television viewing and incident cardiovascular disease: prospective associations and mediation analysis in the EPIC Norfolk Study. PLoS One 2011, 6:e20058.

8. Lee C, Dobson AJ, Brown WJ, Bryson L, Byles J, Warner-Smith P, Young AF: Cohort profile: the Australian longitudinal study on women's health. Int J Epidemiol 2005, 34:987-991.

9. van Uffelen JG, Watson MJ, Dobson AJ, Brown WJ: Sitting time is associated with weight, but not with weight gain in mid-aged Australian women. Obesity 2010, 18:1788-1794.

10. Brown WJ, Burton NW, Marshall AL, Miller YD: Reliability and validity of a modified self-administered version of the Active Australia physical activity survey in a sample of mid-age women. Aust N Z J Public Health 2008, 32:535-541.

11. National Health and Medical Research Council: Australian alcohol guidelines: health risks and benefits. Canberra: Commonwealth of Australia; 2001.

12. Katzmarzyk PT, Church TS, Craig CL, Bouchard C: Sitting time and mortality from all causes, cardiovascular disease, and cancer. Med Sci Sports Exerc 2009, 41:998-1005.

13. Patel AV, Bernstein L, Deka A, Feigelson HS, Campbell PT, Gapstur SM, Colditz GA, Thun MJ: Leisure time spent sitting in relation to total mortality in a prospective cohort of US adults. Am J Epidemiol 2010, 172:419-429.

14. Weller I, Corey P: The impact of excluding non-leisure energy expenditure on the relation between physical activity and mortality in women. Epidemiology 1998, 9:632-635.

15. Pavey TG, Peeters GMEE, Brown WJ: Sitting time and 9-year all-cause mortality in older women. British J Sports Med 2012. doi:10.1136/bjsports2012-091676.

16. Peeters GG, Burton NW, Brown WJ: Associations between sitting time and a range of symptoms in mid-age women. Prev Med 2013, 56:135-141.

17. Danesh J, Saracci R, Berglund G, Feskens E, Overvad K, Panico S, Thompson S, Fournier A, Clavel-Chapelon F, Canonico M, Kaaks R, Linseisen J, Boeing H, Pischon T, Weikert C, Olsen A, Tjonneland A, Johnsen SP, Jensen MK, Quiros $J R$, Svatetz CA, Perez MJ, Larranaga N, Sanchez CN, lribas CM, Bingham S, Khaw KT, Wareham N, Key T, Roddam A, et al: EPIC-Heart: the cardiovascular component of a prospective study of nutritional, lifestyle and biological factors in 520,000 middle-aged participants from 10 European countries. Eur J Epidemiol 2007, 22:129-141.

18. Rosenberg DE, Bull FC, Marshall AL, Sallis JF, Bauman AE: Assessment of sedentary behavior with the international physical activity questionnaire. J Phys Act Health 2008, 5(Suppl 1):S30-S44.

doi:10.1186/1479-5868-10-55

Cite this article as: Herber-Gast et al: Self-reported sitting time is not associated with incidence of cardiovascular disease in a populationbased cohort of mid-aged women. International Journal of Behavioral Nutrition and Physical Activity 2013 10:55.

\section{Submit your next manuscript to BioMed Central and take full advantage of:}

- Convenient online submission

- Thorough peer review

- No space constraints or color figure charges

- Immediate publication on acceptance

- Inclusion in PubMed, CAS, Scopus and Google Scholar

- Research which is freely available for redistribution 